\title{
Differences between Outdoor and Indoor Sound Levels for Open, Tilted, and Closed Windows
}

\author{
Barbara Locher ${ }^{1,+}$, André Piquerez ${ }^{2}$, Manuel Habermacher ${ }^{3}$, Martina Ragettli ${ }^{2,4}$, \\ Martin Röösli 2,4 iD, Mark Brink ${ }^{5}$ (D), Christian Cajochen ${ }^{6}$, Danielle Vienneau ${ }^{2,4}$, \\ Maria Foraster ${ }^{2,4}$, Uwe Müller ${ }^{7}$ and Jean Marc Wunderli ${ }^{1, *}$ \\ 1 Empa, Laboratory for Acoustics/Noise Control, Swiss Federal Laboratories for Materials Science and \\ Technology, 8600 Dubendorf, Switzerland \\ 2 Swiss Tropical and Public Health Institute, 4051 Basel, Switzerland; andipiquerez@hotmail.com (A.P.); \\ martina.ragettli@unibas.ch (M.R.); martin.roosli@unibas.ch (M.R.); danielle.vienneau@unibas.ch (D.V.); \\ maria.foraster@unibas.ch (M.F.) \\ 3 n-Sphere AG, 8045 Zürich, Switzerland; manuel.habermacher@n-sphere.ch \\ 4 Centre for Chronobiology, University of Basel, 4001 Basel, Switzerland \\ 5 Federal Office for the Environment, 3003 Bern, Switzerland; mark.brink@bafu.admin.ch \\ 6 Centre for Chronobiology, Psychiatric Hospital of the University of Basel, 4056 Basel, Switzerland; \\ christian.cajochen@upkbs.ch \\ 7 Deutsches Zentrum für Luft- und Raumfahrt e.V. (DLR), Institut für Luft- und Raumfahrtmedizin, \\ 51147 Köln, Germany; Uwe.Mueller@dlr.de \\ * Correspondence: jean-marc.wunderli@empa.ch; Tel.: +41-58-765-4748 \\ † Current address: Müller-BBM Schweiz AG, 4123 Allschwil, Switzerland; Barbara.Locher@mbbm.com.
}

Received: 17 August 2017; Accepted: 10 January 2018; Published: 18 January 2018

\begin{abstract}
Noise exposure prediction models for health effect studies normally estimate free field exposure levels outside. However, to assess the noise exposure inside dwellings, an estimate of indoor sound levels is necessary. To date, little field data is available about the difference between indoor and outdoor noise levels and factors affecting the damping of outside noise. This is a major cause of uncertainty in indoor noise exposure prediction and may lead to exposure misclassification in health assessments. This study aims to determine sound level differences between the indoors and the outdoors for different window positions and how this sound damping is related to building characteristics. For this purpose, measurements were carried out at home in a sample of 102 Swiss residents exposed to road traffic noise. Sound pressure level recordings were performed outdoors and indoors, in the living room and in the bedroom. Three scenarios-of open, tilted, and closed windows-were recorded for three minutes each. For each situation, data on additional parameters such as the orientation towards the source, floor, and room, as well as sound insulation characteristics were collected. On that basis, linear regression models were established. The median outdoor-indoor sound level differences were of $10 \mathrm{~dB}(\mathrm{~A})$ for open, $16 \mathrm{~dB}(\mathrm{~A})$ for tilted, and $28 \mathrm{~dB}(\mathrm{~A})$ for closed windows. For open and tilted windows, the most relevant parameters affecting the outdoor-indoor differences were the position of the window, the type and volume of the room, and the age of the building. For closed windows, the relevant parameters were the sound level outside, the material of the window frame, the existence of window gaskets, and the number of windows.
\end{abstract}

Keywords: sound level differences indoors/outdoors; correction factors; open window; tilted window; closed window; linear model

\section{Introduction}

Noise exposure prediction models that are used in health effect studies normally yield free field exposure levels outside residences as results. In these models, the sound insulation of buildings is 
neglected. However, to assess the sound exposure of the inhabitants inside buildings, an estimate of the indoor sound level is necessary, as people spend a considerable amount of their time indoors. Indoor sound levels are especially important at night, as they account for awakening and other sleep disturbances caused by outside noise, which are assumed to play a major role in noise-induced health impairments [1-5]. However, little data is available on the difference between indoor and outdoor noise levels. Most health studies therefore rely on outdoor levels [6,7]. Others apply a constant difference in terms of sound levels outdoors and indoors. The latter approach however is a very coarse estimate and does not take into account specific conditions of the dwelling situation, window opening behaviour, and building characteristics. This is a major cause of uncertainty in the prediction of the "true" noise exposure and can produce exposure misclassification in studies of noise-induced health effects, particularly during the night-time. Amundsen et al. showed that changes in sound insulation have a significant effect not only on sleep disturbance but also on annoyance ratings $[8,9]$. In order to overcome these limitations, Foraster et al. for example introduced different correction factors to estimate the indoor noise exposure from outdoor noise, which however needs further validation [10]. Hence, better knowledge of the noise reduction by buildings would be useful for future epidemiological research in order to reduce exposure misclassification. If the extent of exposure misclassification is independent of health status and is thus non-differential, health effects are most likely underestimated. If, however, exposure misclassification depends on health status, bias in any direction is possible, depending on the direction of the misclassification. A common coping strategy for example is to close the windows [11-13]. Hence, a plausible assumption for such differential exposure misclassification is the possibility that noise-sensitive individuals who are more vulnerable to health effects are likely to more often close the windows in their dwellings. As a consequence, their noise exposure is more strongly overestimated than for people with open windows. This again, would result in an underestimation of the true exposure-response association [14].

So far, only a few studies have assessed façade sound insulation compared to outdoor noise levels for open or tilted window positions. In a field study performed in Australia, an average level difference for open windows of $11 \mathrm{~dB}(\mathrm{~A})$ resulted [15]. Two studies performed at the German DLR-Institut für Luft- und Raumfahrtmedizin (The German Aerospace Center (DLR) is the national aeronautics and space research centre of Germany) [16-18] reported similar values, ranging from 10 to $13 \mathrm{~dB}(\mathrm{~A})$ depending of the type of noise source. In the same two studies, tilted, i.e., slightly open windows were also tested. While the measurements of 2006 resulted in differences of 14 and $15 \mathrm{~dB}(\mathrm{~A})$ for road and air traffic, respectively, the follow-up study yielded average values of 18 to $19 \mathrm{~dB}(\mathrm{~A})$ for road and railway traffic. For aircraft noise, Jansen et al. [19] as well as the Swiss Federal Office for the Environment (FOEN) [20] recommend assuming a level difference between the outdoors and indoors in the case of tilted windows of $15 \mathrm{~dB}(\mathrm{~A})$. For the same noise source, Maschke et al. [21] derived a mean difference in level of $12 \mathrm{~dB}(\mathrm{~A})$ for tilted window positions based on loudspeaker experiments. The European Environment Agency summarizes these results in its "Guidelines for noise exposure assessment" [22] where an attenuation of $5-10 \mathrm{~dB}(\mathrm{~A})$ is recommended for open windows and 10-15 $\mathrm{dB}(\mathrm{A})$ for slightly open windows.

For closed windows, numerous building acoustic studies are at hand, showing the major influence of the façade type on the resulting sound insulation (see for example [22,23]). In addition to the room size, the reverberation time as well as window area play an important role [24-26]. Licitra et al. [27] performed an extensive measurement study on railway noise in Pisa, with measurements inside and outside of buildings. Pabst [28] gives differences for closed windows ranging from 24 to $35 \mathrm{~dB}(\mathrm{~A})$, for aircraft noise. This study also showed that the same window can have a different sound level reduction depending on the aircraft type (up to $\pm 3 \mathrm{~dB}(\mathrm{~A})$ ). The previously mentioned studies by DLR $[16,17]$ yielded mean sound insulations in the case of closed windows ranging from 26 to $37 \mathrm{~dB}(\mathrm{~A})$ depending on the sound source and the façade type. Scamoni et al. [29] analyzed a dataset of 334 locations, resulting in a mean outdoors-indoors difference for closed windows of $31 \mathrm{~dB}(\mathrm{~A})$ and values ranging from a minimal difference of 18 to a maximal difference of $42 \mathrm{~dB}(\mathrm{~A})$. As a conservative 
estimate, the FOEN [20] recommends assuming an outside-inside level difference of $25 \mathrm{~dB}(\mathrm{~A})$, in order to get an estimate of the probability of awakening as a reaction. The influence of local building standards on the resulting sound insulation can be studied when comparing buildings, which have been erected for a specific purpose. While only limited information is available for apartments, there are various studies that investigated the acoustic properties of schools [30-35] indicating variations in sound insulation of more than $10 \mathrm{~dB}(\mathrm{~A})$.

As a consequence, it can be stated that for open and tilted windows, only limited data is available and that for closed windows, the necessary information for an accurate prediction of the sound insulation in a specific situation is typically not at hand in the case of health effect studies with numerous participants. This is a limitation for health risk research as noise level at the ear of the inhabitant is considered most relevant from a biological point of view. Thus, better knowledge of building damping would enable a more accurate prediction of indoor noise exposure from outside values. Therefore, the aim of the present study is to determine representative differences between the sound level outdoors and indoors for open, tilted, and closed windows for buildings in Switzerland based on measurements (see also [36]). The most relevant parameters for the outdoor-indoor differences shall be determined and a statistical model shall be developed to predict the sound level difference as a function of dwelling and exposure characteristics, which may then later be applicable for refined epidemiological analyses. This study has been performed as a follow-up project of the nationwide assessment of road, railway, and aircraft noise exposure conducted within the Short and long-term effects of Transportation Noise Exposure (SiRENE) study $[6,7,37,38]$.

\section{Methods}

\subsection{Measurements}

From the 5592 respondents of the socio-acoustic survey of SiRENE [38], 102 participants that agreed to be contacted again were visited at home. Interviews on noise annoyance, coping strategies, and sound level measurements were carried out by three research assistants between May and November 2016. The analysis of these interviews however is not part of this paper. Inclusion criteria were that the participants lived nearby heavily used roads, and the $L_{d e n}$ at the highest exposed façade had to be $\geq 50 \mathrm{~dB}(\mathrm{~A})$ to ensure sufficient outdoor noise to be detected inside. Measurements were carried out in apartments at different floor levels. Over $80 \%$ of the measurements were performed at ground floor up to the third floor. The remaining $20 \%$ of measurements were taken between the fourth and seventh floors.

The sound recordings were performed simultaneously outdoors, with the microphone flush mounted in the middle of the outer face of a window, and indoors, if possible in the bedroom at the position of the pillow (hypothetical position of sleeper's ear). In the case the sleeping room was not the room most exposed to noise, the measurements were repeated in the living room $(\mathrm{N}=55)$ with the microphone placed in the middle of the room at a height of approximately $1.5 \mathrm{~m}$. Therefore, three scenarios with open, tilted and closed windows were recorded. As the aim of this study was to determine sound level differences between the indoors and outdoors, but not to establish a representative long-term sound exposure, it was decided to take short, but fully controlled measurements in order to minimize the impact of indoor noise sources on the measurements. Each scenario was therefore measured over three minutes. During the measurements, great attention was given to minimize any sounds originating from inside the building. If there were interfering noises inside or there were unwanted sound sources other than road traffic noise outside, the measurements were stopped and repeated. Measurements were not taken at a specific time of day, but according to the availability of the participants, they were typically taken in the evening hours. Altogether, measurements were carried out in 157 rooms in 102 buildings. About $80 \%$ of these were in flats in apartment buildings and $20 \%$ were single-family houses. 
For the outdoor measurements, class II Noise Sentry RT (Convergence Instruments, Sherbrooke, QC, Canada) sound level meters were used, which logged A-weighted $1 \mathrm{~s} L_{e q}$ levels. This device has a dynamic measurement range of 31 to $117 \mathrm{~dB}$. This class II sound level meter was chosen because these devices were used in the same time for long-term measurement over one week to validate the noise exposure modeling of SiRENE [39]. As the outdoor microphone was flush-mounted a frequency-independent pressure doubling can be assumed. Therefore, a correction of $-6 \mathrm{~dB}$ was applied to get free field conditions. The indoor measurements were performed with the class I sound level meter, type NTI XL2 (NTi Audio AG, Schaan, Liechtenstein) with a free field microphone. This device has a dynamic measurement range of 17 to $138 \mathrm{~dB}$. One-third octave-band spectra from $50 \mathrm{~Hz}$ to $10 \mathrm{kHz}$ were recorded indoors with a temporal resolution of one second $\left(1 \mathrm{~s} L_{e q}\right)$. Both sound level meters were calibrated before each measurement.

For each recording situation, additional parameters describing the room and sound insulation properties were collected using a pre-defined protocol. These parameters were chosen as possible predictors based on consultation of experts in building acoustics and our own experience. Table 1 shows a complete list of the parameters. Figure 1 shows a typical window with two sashes (the moveable part of the window). Overall, $87 \%$ of the analyzed windows had two sashes and only $13 \%$ had only one sash. The opening angle of tilted windows was typically about 5-10 degrees.
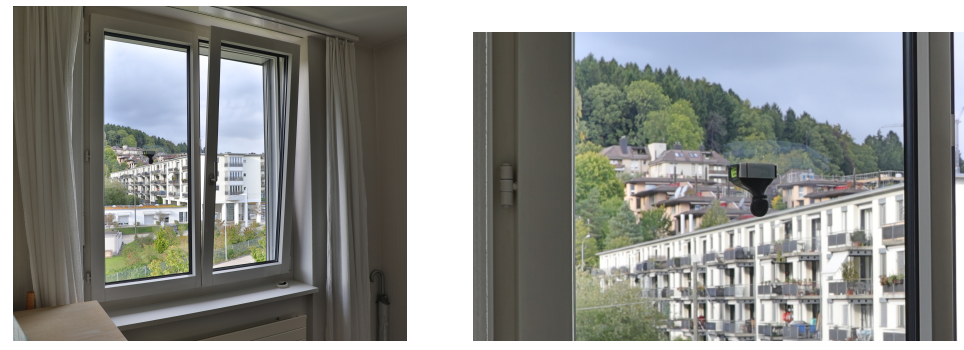

Figure 1. (Left) An example of a typical window with two sashes in a tilted position. The Noise Sentry is mounted on the left side, in the middle of the window pane; (Right) Close-up showing the Noise Sentry mounted on the window.

Table 1. Considered parameters describing the room and its sound insulation characteristics used as possible predictors for sound level differences outdoors/indoors.

\begin{tabular}{|c|c|c|c|}
\hline Parameter & Type & Levels & No. of Levels \\
\hline Window position & Categorical & Open, tilted, closed & 3 \\
\hline Floor level & Continuos & $0,1,2$, etc. & - \\
\hline Room type & Categorical & Sleeping room, living room, kitchen/dining room & 3 \\
\hline Orientation of window towards source & Categorical & frontal, lateral $\left(90^{\circ}\right)$, opposite side & 3 \\
\hline Distance to source & Continuous & Distance in $\mathrm{m}$ & - \\
\hline Microphone position inside & Categorical & Corner, close to wall, free in the room & 3 \\
\hline Distance microphone inside-window & Continuous & Distance in $\mathrm{m}$ & - \\
\hline Window-frame & Categorical & Wood, synthetic material, metal & 3 \\
\hline Existence of window gaskets & Categorical & yes, no, unknown & 3 \\
\hline Condition of window gaskets & Categorical & Good, mediocre, bad, unknown & 4 \\
\hline No. of window glasses & Categorical & Single, double, triple glazing & 3 \\
\hline Type of window & Categorical & 1 sash (moveable part of the window), 2 sashes & 2 \\
\hline Type of façade & Categorical & Façade with single windows, band of windows, glass front & 3 \\
\hline No. of windows in room & Continuous & $1,2,3$, etc. & - \\
\hline Proportion of glazed area & Continuous & Percentage, relative to the wall area & - \\
\hline Volume of the room & Categorical & $<15,15-35,35-60,60-150 \mathrm{~m}^{3}$ & 4 \\
\hline Type of building & Categorical & $\begin{array}{l}\text { single-family house, detached apartment building, } \\
\text { continuous block of flats }\end{array}$ & 3 \\
\hline Age of building & Categorical & $>40,20-40,<20$ years, unknown & 4 \\
\hline Period of renovation & Categorical & 1971-1980, 1981-1990, 1991-2000, not renovated, unknown & 5 \\
\hline Aeration & Categorical & Window ventilation, artificial ventilation & 2 \\
\hline Room characteristics & Categorical & Corner room, top floor with pitched roof area, other & 3 \\
\hline
\end{tabular}




\subsection{Calculation of the Sound Level Differences between the Outdoors and Indoors}

To estimate the mean difference between the sound pressure level outdoors and indoors, the following procedure was carried out. For a measurement period of approximately three minutes per room and window scenario, an energetically mean sound level was calculated for intervals of $10 \mathrm{~s}$. This was primarily done in order to account for a possible slight time offset due to inexact synchronization between the devices ( $\pm 2 \mathrm{~s}$ ). For each $10 \mathrm{~s} L_{\text {Aeq }}$, the difference between the outdoors and indoors was calculated. These approximately 18 data points (in $3 \mathrm{~min}$ ) were plotted, a linear fit was applied, and the correlation between the sound levels outdoors and indoors was evaluated (Figure 2 shows an example). All situations with an $R^{2} \geq 0.45$ were classified as potentially valid measurements. As a second criterion, the slope $(\mathrm{dB} / \mathrm{dB})$ had to be close to 1 . For measurements with a slope $<0.5$ or $>1.5$ it was visually verified whether a plausible correlation between the indoors and outdoors existed. This leads to the general restriction that more often in measurements with closed windows, windows that have a high sound insulation and places with low sound levels outdoors are not considered in the statistical analyses. From the $\Delta 10 s L_{A e q}($ out $-i n)$ the median was taken as representative difference for the specific situation.

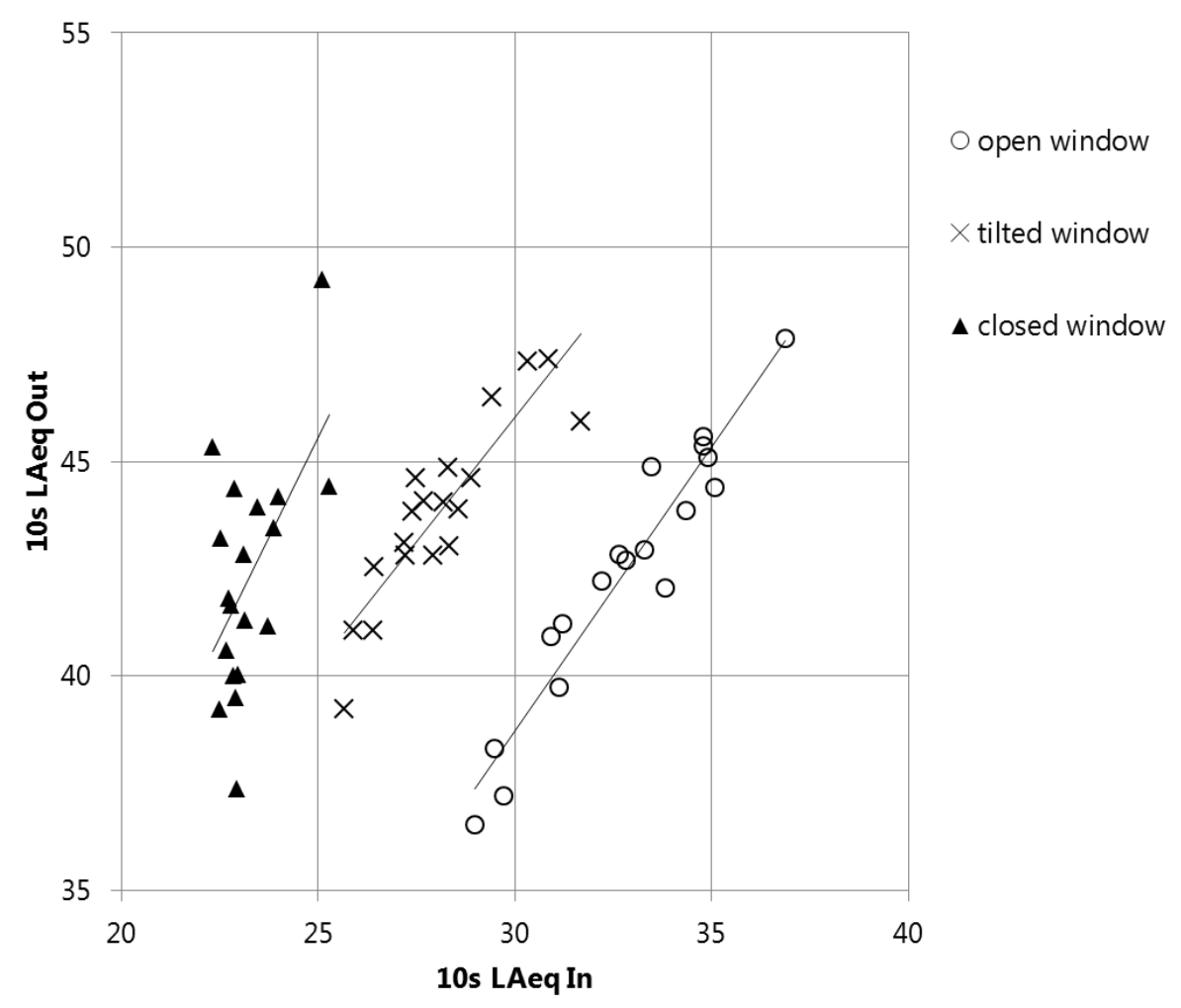

Figure 2. Example of measurement data (ID 0342): $10 \mathrm{~s}_{\mathrm{Aeq}}$ outdoors (corrected by $-6 \mathrm{~dB}$ ) versus indoors. In this case the median outdoor-indoor difference for the open (circles, $R^{2}=0.92$ ) and tilted (crosses, $R^{2}=0.79$ ) windows with $R^{2} \geq 0.45$ are included in the further analysis. As there is no clear outdoor-indoor correlation for the closed window (triangles, $R^{2}=0.32$ ), this measurement is not considered in the statistical analyses.

\subsection{Statistical Analyses}

The statistical analyses were carried out with $\mathrm{R}$ version 3.1.3. In a first step, a boxplot for each window position was plotted and analyzed. Outliers were removed following Tukey's method [40]. Therefore, outliers were defined as outside 1.5 times the interquartile range (IQR). The method was applied on each window position separately. 
A multiple linear regression analysis was used to model the influence of the predictors listed in Table 1 on the outdoor-indoor sound level difference. These models combine categorical variables, continuous variables, and interactions to predict the dependent variable $\left(\Delta L_{A e q}\right.$ out $\left.-i n\right)$. The parameters volume of the room and age of the building were only available in categories. Therefore, these two actually continuous parameters were considered as categorical. The assumption that the errors are normally distributed was tested and a linear model ( $\mathrm{lm}$ in $\mathrm{R})$ was applied.

The process of sound transmission is fundamentally different in the case of closed windows. With open and tilted windows, the opening is the dominant sound path and material properties can in most cases be neglected. With windows closed, properties like the composition of the multi-layer glazing, the material of the window frame, window gaskets, etc. are important. This results in many potential influencing parameters and interactions. Therefore, separate regression models were established for closed windows on the one hand and for open and tilted windows on the other hand. The variable selection was done by a stepwise approach with the Akaike Information Criteria (AIC), where the model with the lowest AIC was preferred (function step in R). Variables were retained if statistically significant ( $p$-value $\leq 0.05$ ). Compliance with the model assumptions was confirmed by visual inspection of the residual plots (Tukey-Anscombe plot, normal plot, and scale-location plot). Possible leverage or influential data points were detected by inspection of the leverage plot.

\section{Results}

\subsection{A-Weighted Sound Level Differences between Outdoors and Indoors}

From the measurements in 157 rooms, 115 measurements for open windows, 116 measurements for tilted windows, and 76 measurements for closed windows were valid. Results for the outdoor-indoor differences are shown in Figure 3, with corresponding values given in Table 2. In brief, the median \pm standard deviation was $10.0 \pm 2.9 \mathrm{~dB}(\mathrm{~A}), 15.8 \pm 2.7 \mathrm{~dB}(\mathrm{~A})$, and $27.8 \pm 4.4 \mathrm{~dB}(\mathrm{~A})$ for open, tilted, and closed windows, respectively. For the statistical analyses, the six outliers in the boxplots, defined as outside 1.5 times the interquartile range, were removed.

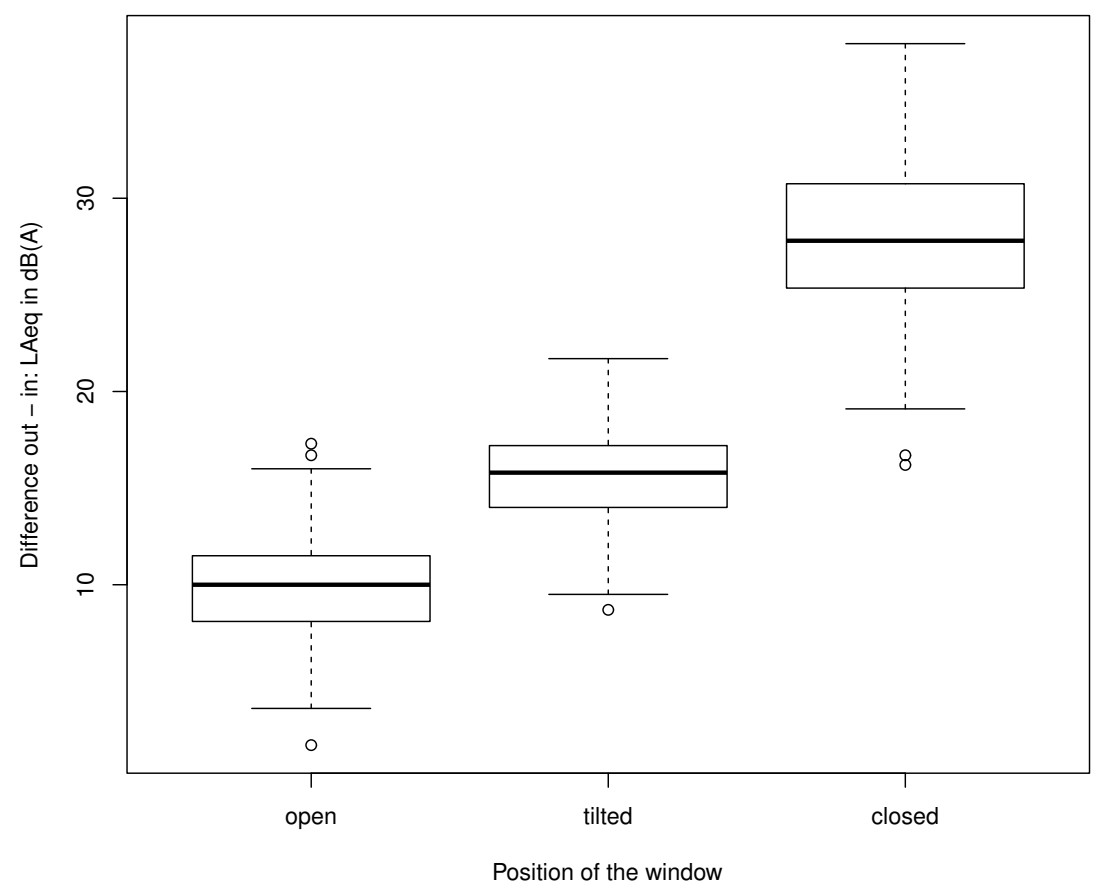

Figure 3. Boxplots of all valid data showing the median (horizontal line in boxes), the $25 \%$ and $75 \%$ quantiles (lower and upper boundaries of boxes), the whiskers comprising the data within 1.5 times the interquartile range, and outliers outside the whiskers. 
Table 2. Differences of the sound levels outdoors (corrected by $-6 \mathrm{~dB}$, representing free field conditions) and indoors for the different window positions and the corresponding number of measurements. (SD: standard deviation)

\begin{tabular}{cccccc}
\hline \multirow{2}{*}{ Window Position } & \multicolumn{3}{c}{$\mathbf{\Delta 1 0} \boldsymbol{s} \mathbf{L}_{\text {Aeq }}($ out $-\mathbf{i n})$} & \multirow{2}{*}{ Number of Measurements } \\
\cline { 2 - 5 } & Median (25\%, 75\% Quantile) & Min & Max & SD & 115 \\
open & $10.0(8.1,11.5)$ & 1.7 & 17.3 & 2.9 & 116 \\
tilted & $15.8(14.0,17.2)$ & 8.7 & 21.7 & 2.7 & 76 \\
closed & $27.8(25.4,30.8)$ & 16.2 & 38.0 & 4.4 & 307 \\
\hline all & & & & 307 \\
\hline
\end{tabular}

\subsection{Spectral Sound Level Differences between the Outdoors and Indoors}

Figure 4 shows a statistical representation of the measured $L_{e q}$ indoors in one-third octave bands from 50 to 10,000 Hz for open, tilted, and closed windows. Both the open and tilted situations show maxima around $1 \mathrm{kHz}$, with a slight decrease of levels towards lower frequencies and a more prominent decrease of levels towards higher frequencies. In contrast, for closed windows a widely flat spectrum is shown.

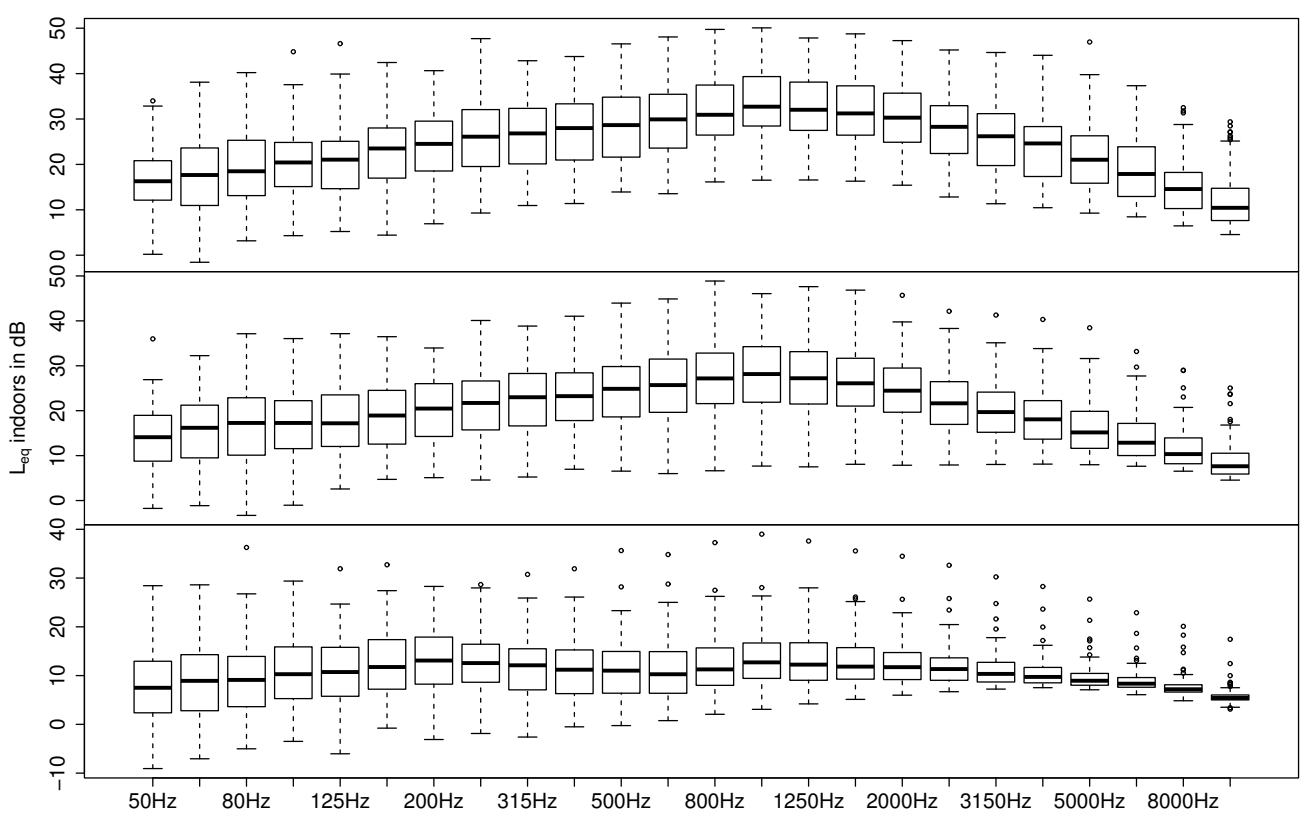

Figure 4. $L_{e q}$ indoors in one-third octave bands for open (top), tilted (middle), and closed windows (bottom) of all valid measurements. Boxplots show the median (horizontal line in boxes), 25\% and 75\% quantiles (lower and upper boundaries of boxes), whiskers comprising the data within 1.5 times the interquartile range, and outliers outside the whiskers show each one-third octave band.

As mentioned in Section 2.1 only A-weighted levels are available for the outside measurement position. In order to still get a frequency-dependent difference in level between the outdoors and indoors, an estimation of the spectra outdoors was done. For that purpose, we assumed a typical road noise spectrum in a distance $<200 \mathrm{~m}$ with $5 \%$ heavy vehicles and a velocity of $50 \mathrm{~km} / \mathrm{h}$ based on the CNOSSOS road traffic model [41]. The resulting spectral outdoor-indoor differences for open, tilted, and closed windows are shown in Figure 5. In the case of open and tilted windows, we see more or less flat curves with a frequency-independent attenuation, which is in good agreement with the literature $[18,42]$. For closed windows, in contrast the noise reduction seems to be higher for frequencies ranging from 400 to $4000 \mathrm{~Hz}$. While a smaller damping at lower frequencies can be expected for situations with closed windows (see for example [23,43], a decay towards higher 
frequencies seems to be counter-intuitive. This finding however can be explained by the residual sound of the measuring device in combination with the very low sound pressure level. As can be seen in Figure 4 the levels drop below $10 \mathrm{~dB}$ at very low as well as very high frequencies. The sound level meter type NTI XL2 on the other hand exhibits a residual noise of more than $10 \mathrm{~dB}$ at the one-third octave band of $63 \mathrm{~Hz}$ and below, and a residual noise of more than $6 \mathrm{~dB}$ at one-third octave bands of $4 \mathrm{kHz}$ and higher. Consequently, it can be concluded that at these frequencies residual noise influenced the measurement and that the real sound insulation is therefore underestimated. Even though the mentioned frequency range is not dominant with respect to A-weighted levels, a slight underestimation of the resulting level difference between outside and inside must be assumed for the situation of closed windows as given in Figure 3 and Table 2.

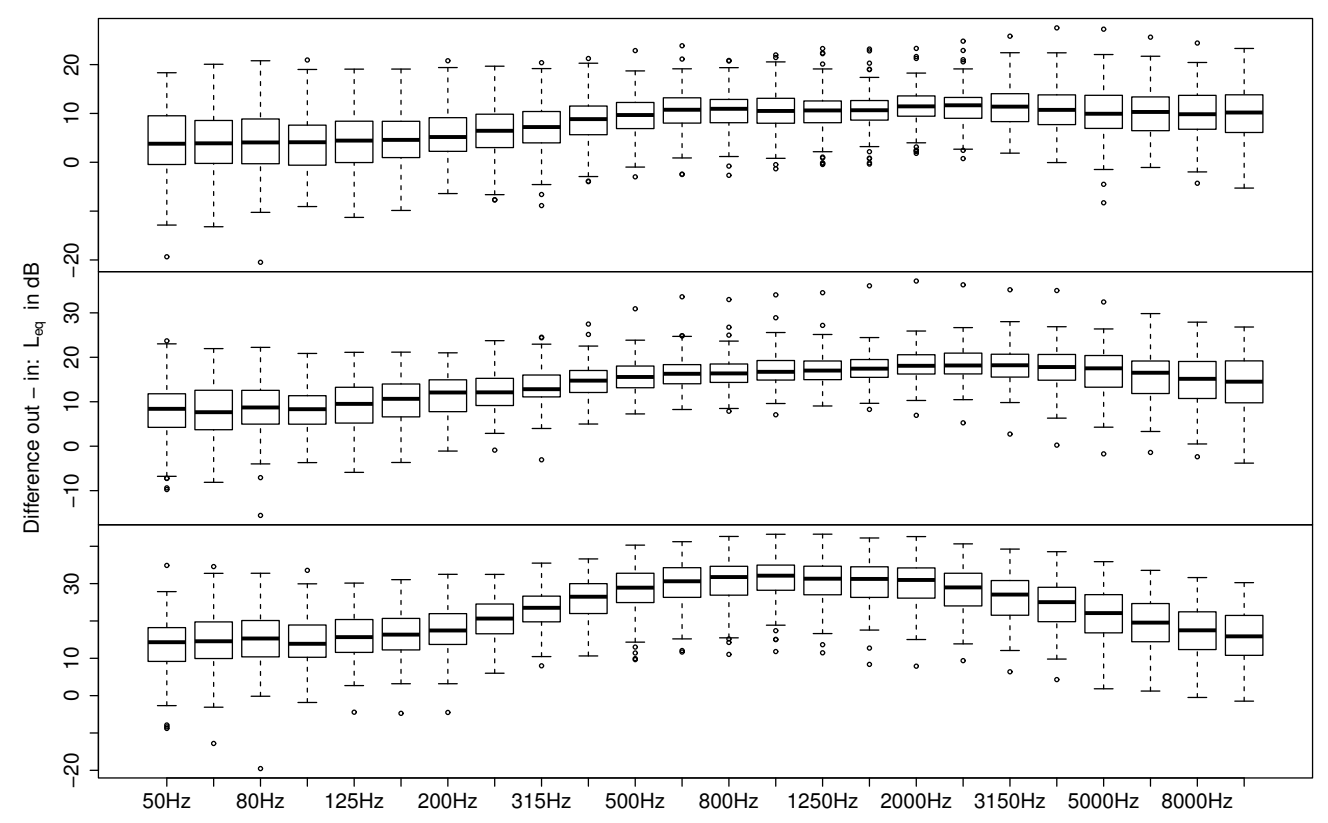

Figure 5. Outdoor-indoor differences for the open (top), tilted (middle), and closed windows (bottom) for all valid measurements. Boxplots show the median (horizontal line in boxes), $25 \%$ and $75 \%$ quantiles (lower and upper boundaries of boxes), whiskers comprising the data within 1.5 times the interquartile range, and outliers outside the whiskers for each one-third octave band.

\subsection{Linear Regression Model for Open and Tilted Windows}

Based on the available predictor variables in Table 1, the following linear model was found to be appropriate:

$$
\Delta L_{\text {Aeq }} \text { out }- \text { in }=\beta_{0}+\text { window }+ \text { room }+V+\text { age } \quad[\mathrm{dB}(\mathrm{A})]
$$

In this equation, the dependent variable is the level difference $\Delta L_{A e q}$ out $-i n, \beta_{0}$ is the overall mean of this difference, and window position (open or tilted), room type, volume (V), and age are fixed categorical factors. These parameters have a significant effect with the following $p$-values: the window position, i.e., open or tilted with $p<0.001$, the type of room with $p<0.001$, the age of the building with $p=0.001$, and the volume of the room with $p=0.01$ (see Table 3 ). No significant interactions between the different significant parameters were detected.

This linear model yields an explained variance of $65 \%$ (adjusted $R^{2}$ ). The position of the window accounted for $58 \%$ of the variability in the data. Another $7 \%$ of the variance was explained by the room type (5\%) and the age of the building $(2 \%)$. The volume of the room does not explain much of the variability $(1 \%)$. 
By visual inspection of the residual plots, the compliance with the model assumptions could be confirmed. The normal distribution of the residuals was also confirmed by the Lilliefors (Kolmogorov-Smirnov) normality test $(p=0.744)$. No leverage or influential data point was detected.

A small influence on the outdoor-indoor differences however is attributed to the mean sound level outdoors ( $p<0.001$, explaining $3 \%$ of the variance). This critical finding is discussed in Section 4.2. The original category $35-60 \mathrm{~m}^{3}$ did not show a significant difference to the smaller rooms $\left(15-35 \mathrm{~m}^{3}\right)$ in the parameter estimate. Therefore, we reclassified the room volume into only two categories, namely $<60 \mathrm{~m}^{3}$ and $60-150 \mathrm{~m}^{3}$.

Table 3. Parameter estimates of the regression model for outdoor-indoor sound level differences for open and tilted windows. (V: volume. CI: confidence interval.)

\begin{tabular}{|c|c|c|c|c|c|c|}
\hline Parameter & Symbol in Equation (1) & Coeff. & $95 \% \mathrm{CI}$ & Std. Error & $t$ Value & $\operatorname{Pr}(>|t|)$ \\
\hline Intercept & $\beta_{0}$ & 8.5 & {$[7.5 ; 9.5]$} & 0.5 & 16.8 & $<0.001$ \\
\hline Window position & $\begin{array}{l}\text { window }=\text { open } \\
\text { window }=\text { tilted }\end{array}$ & $\begin{array}{l}0^{a} \\
6.1\end{array}$ & {$[5.4 ; 6.7]$} & 0.3 & 19.1 & 0.001 \\
\hline Room & $\begin{array}{c}\text { room }=\text { bedroom } \\
\text { room }=\text { kitchen } / \text { dining room } \\
\text { room }=\text { living room }\end{array}$ & $\begin{array}{c}0^{a} \\
-5.1 \\
-1.1\end{array}$ & $\begin{array}{l}{[-7.3 ;-2.9]} \\
{[-1.9 ;-0.4]}\end{array}$ & $\begin{array}{l}1.1 \\
0.4\end{array}$ & $\begin{array}{l}-4.5 \\
-3.0\end{array}$ & $\begin{array}{c}<0.001 \\
0.003\end{array}$ \\
\hline Room volume & $\begin{array}{c}\mathrm{V}=<60 \mathrm{~m}^{3} \\
\mathrm{~V}=60-150 \mathrm{~m}^{3}\end{array}$ & $\begin{array}{l}0^{a} \\
1.2 \\
\end{array}$ & {$[0.2 ; 2.1]$} & 0.5 & 2.4 & 0.018 \\
\hline Age of building & $\begin{array}{l}\text { age }<20 \text { years } \\
\text { age }=20-40 \text { years } \\
\text { age }>40 \text { years }\end{array}$ & $\begin{array}{l}0^{a} \\
1.7 \\
1.9\end{array}$ & $\begin{array}{l}{[0.7 ; 2.7]} \\
{[0.9 ; 2.9]}\end{array}$ & $\begin{array}{l}0.5 \\
0.5\end{array}$ & $\begin{array}{l}3.3 \\
3.7\end{array}$ & $\begin{array}{c}0.001 \\
<0.001\end{array}$ \\
\hline
\end{tabular}

$0^{a}$ Reference values.

\subsection{Linear Regression Model for Closed Windows}

For closed windows the main influence on the indoor-outdoor differences is attributed to the mean sound level outdoors with an $R^{2}$ of 0.55 (see Figure 6). This critical finding is discussed in detail in Section 4.3.

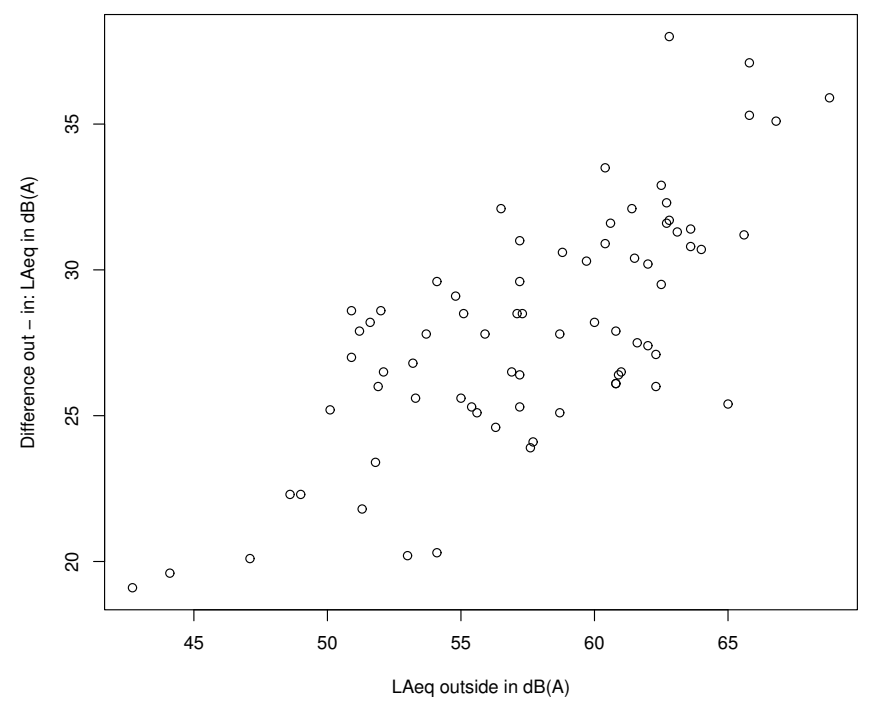

Figure 6. Plot showing the outdoor-indoor differences for measurements with closed windows as a function of the energetically averaged sound level outdoors. Note: In Section 2.1 it was stated that only situations with $L_{d e n}$ levels $\geq 50 \mathrm{~dB}(\mathrm{~A})$ were selected. However, the plot also shows considerably lower levels. This alleged contradiction is due to the fact that measurements were not only performed at the most exposed façades but also at the averted façades. In addition, short-term Leq cannot directly be compared with $L_{d e n}$, as the latter represent long-term averages and also include penalizations. 
If we include the sound level outdoors as a parameter, despite the mentioned critical finding, the following linear model for closed windows is derived:

$$
\Delta L_{\text {Aeq }} \text { out }- \text { in }=\beta_{0}+\beta_{1} \cdot \text { windows }+\beta_{2} \cdot L_{\text {Aeq }} \text { out }+ \text { frame }+ \text { gaskets } \quad[\mathrm{dB}(\mathrm{A})]
$$

In this equation, the dependent variable is $\Delta L_{\text {Aeq }}$ out $-i n, \beta_{0}$ is the intercept, the material of the window frame (frame) and the existence of window gaskets (gaskets) are fixed factors, and the number of windows (windows) and the $L_{A e q}$ outdoors are the covariates with the corresponding regression coefficients $\beta_{1}$ and $\beta_{2}$. The number of windows $(p=0.02)$, the sound level outdoors $(p \leq 0.001)$, the material of the window frame $(p=0.001)$ and the existence of window gaskets $(p=0.05)$ significantly influence the outdoor-indoor difference. No significant interactions between the different parameters were detected. The model coefficients are presented in Table 4 . This linear model yields an explained variance of $62 \%$ (adjusted $R^{2}$ ).

By visual inspection of the residual plots, the compliance with the model assumptions could be confirmed. The normal distribution of the residuals was also confirmed by the Lilliefors (Kolmogorov-Smirnov) normality test $(p=0.263)$. One measurement with a room volume smaller than $15 \mathrm{~m}^{3}$ was excluded, as this was the only measurement in such a small room and generated a leverage of one. After excluding this data point, no other leverage or influential data point was present in the leverage plot. The category metal window frames did not show a significant difference to wooden window frames in the parameter estimate. Therefore we put synthetic and metal window frames together in one category, representing newer windows as compared to wooden window frames.

Table 4. Parameter estimates of the regression model for indoor-outdoor sound level differences for closed windows.

\begin{tabular}{|c|c|c|c|c|c|c|}
\hline Parameter & Symbol in Equation (2) & Coeff. & $95 \% \mathrm{CI}$ & Std. Error & $t$ Value & $\operatorname{Pr}(>|t|)$ \\
\hline Intercept & $\beta_{0}$ & -3.03 & {$[-9.2 ; 3.2]$} & 3.11 & -1.0 & 0.334 \\
\hline Number of windows & $\beta_{1}$ & -0.93 & {$[-1.7 ;-0.16]$} & 0.38 & -2.4 & 0.018 \\
\hline$L_{\text {Aeq }}$ outdoors & $\beta_{2}$ & 0.55 & {$[0.4 ; 0.7]$} & 0.05 & 10.2 & $<0.001$ \\
\hline \multirow{2}{*}{ Material of the window-frame } & frame $=$ wood & $0^{a}$ & & & & \\
\hline & frame = synthetic $/$ metal & 1.91 & {$[0.7 ; 3.1]$} & 0.59 & 3.2 & 0.002 \\
\hline \multirow{2}{*}{ Existence window gaskets } & gaskets = yes & $0^{a}$ & & & & \\
\hline & gaskets $=$ no & -2.32 & {$[-4.6 ; 0.0]$} & 1.15 & -2.0 & 0.050 \\
\hline
\end{tabular}

\section{Discussion}

\subsection{Sound Level Differences between the Outdoors and Indoors}

In this study, over 300 measurements were carried out at people's homes in a sample of more than 100 Swiss residents. The median differences between sound levels outdoors and indoors were $10.0 \pm 2.9 \mathrm{~dB}(\mathrm{~A})$ for open, $15.8 \pm 2.7 \mathrm{~dB}(\mathrm{~A})$ for tilted, and $27.8 \pm 4.4 \mathrm{~dB}(\mathrm{~A})$ for closed windows. The ranges from the minimal to the maximal values were 16,13 , and $22 \mathrm{~dB}(\mathrm{~A})$ for open, tilted, and closed windows, respectively. In case of closed windows, the sound insulation depended very much on building properties, especially the windows (glazing, material of window frame, window gaskets, etc.). This means that for a specific situation the real difference can deviate significantly from the median difference between the sound level outdoors and indoors, as measured in our sample.

In Table 5, these results are compared with the studies already mentioned in the introduction. Most studies $[15,16,18,29]$ used a measurement position outdoors 1 to $2 \mathrm{~m}$ from the front of the façade. In order to correct for reflections from the building façade, Ryan et al. [15] subtracted $2.5 \mathrm{~dB}(\mathrm{~A})$ to get free field conditions. In the DLR-studies $[16,18]$ a correction of $-3.0 \mathrm{~dB}(\mathrm{~A})$ was applied. Hence, Ryan et al. assumed a prominent reflection from the building with a slightly lower intensity than direct sound, while Müller et al. assumed a doubling of the sound intensity by the 
building reflection. The results published by Scamoni et al. [29] originally did not include a correction to free field levels. Therefore, in order to get a better comparability $3.0 \mathrm{~dB}(\mathrm{~A})$ were subtracted for the representation in Table 5.

- A comparison of the values for open window situations shows in general a good agreement between the different studies, with a range of levels from 10 to $13 \mathrm{~dB}(\mathrm{~A})$. The deviation between the resulting averages is rather small, when comparing it with the substantial spread of the individual values within the studies.

- For tilted windows the resulting outside-inside differences are slightly greater, ranging from 14 to $19 \mathrm{~dB}(\mathrm{~A})$. However, the results between the studies still look consistent. The additional sound insulation effect of a tilted window compared to an opened one can consequently be deduced as $4-6 \mathrm{~dB}(\mathrm{~A})$ on average.

- For closed window situations, the resulting averages between the different studies are rather close, ranging from 26 to $31 \mathrm{~dB}(\mathrm{~A})$. Hence, the effect of closing windows, compared to an open window situation, results on average in a level decrease inside the building of $16-18 \mathrm{~dB}(\mathrm{~A})$.

Even though the different studies yielded comparable averages in the case of closed windows also, it has to be mentioned that the individual spread of measured differences within the studies was much larger than for open or tilted situations. This of course reflects the strong influence of the sound insulation properties of the different window and façade types. Some studies $[15,18]$ also suggested an influence of the window and façade type for situations with open and tilted windows. To our understanding, such findings are rather caused by measurement uncertainties, the small number of samples, and other influencing parameters. The sound insulation of façade elements as well as window glazings is generally significantly greater than the measured level differences according to Table 5. This confirms the assumption that the dominating sound path is in both cases through the opening. The sound insulation spectra depicted in Figure 5 with a rather frequency-independent level reduction also indicate that the source spectrum cannot be a major source of influence. Other factors however are likely to play a significant role and are responsible for the differences between studies and reported situations. To our understanding, the following three aspects are most important:

- We are convinced that the angle of sound incidence, in combination with the orientation of the opening of the window, is primarily responsible for the stated source-specific effects.

- The window size and the opening angle define the opening area available for the sound passage and hence the incoming sound intensity.

- The level inside is not only defined by the incoming sound intensity but also by the room acoustic conditions in the receiving room, primarily the reverberation time and the room size.

In the DLR studies, all measurements were done in sleeping rooms with rather small windows in comparison for example to our study. Other studies (for example [15,29]) included other room types like empty rooms, bathrooms, offices, nurseries, and schools with a wide variety of room characteristics. Last but not least, the measured quantity can also have an influence on the resulting sound level differences. This effect however is assumed to be rather small. The DLR study of 2006 [16] identified an average difference between maximum sound pressure levels $S P L_{A S \max }$ and equivalent continuous sound pressure level $L_{\text {Aeq }}$ of $\leq 0.5 \mathrm{~dB}(\mathrm{~A})$.

The recommendations of the European Environment Agency [22] and the FOEN [20] are in good agreement with the study results for tilted windows. However, for open window situations the range of $5-10 \mathrm{~dB}(\mathrm{~A})$ given by [22] seems rather low. Also, the proposed difference in level for closed windows of $25 \mathrm{~dB}(\mathrm{~A})$ proposed by the FOEN [20] seems rather conservative. While such a cautious choice might be appropriate for noise legislation purposes, it is not advisable for epidemiological studies as it introduces a systematic bias. 
Table 5. Differences in the sound levels outdoors and indoors: a comparison with other studies. The values in brackets give the number of analyzed locations. (DLR: German Aerospace Center.)

\begin{tabular}{|c|c|c|c|c|c|c|c|c|c|c|}
\hline \multirow{2}{*}{$\begin{array}{l}\text { Window } \\
\text { Position }\end{array}$} & \multirow{2}{*}{ This Study } & \multicolumn{3}{|c|}{ DLR 2010 [18] } & \multicolumn{2}{|c|}{ DLR 2006 [16] } & \multirow{2}{*}{$\begin{array}{c}\text { Scamoni } \\
2014[29] \\
\text { Reference Road }\end{array}$} & \multirow{2}{*}{$\begin{array}{c}\text { Ryan } \\
2011[15]\end{array}$} & \multirow{2}{*}{$\begin{array}{r}\begin{array}{c}\text { Maschke } \\
2010[21]\end{array} \\
\text { Aircraft }\end{array}$} & \multirow{2}{*}{$\begin{array}{c}\text { BUWAL } \\
1998 \text { [20] } \\
\text { Aircraft }\end{array}$} \\
\hline & & Freight Trains & Passenger Trains & Road & Road & Aircraft & & & & \\
\hline open & 10.0 (115) & $11.3(4)$ & $11.9(4)$ & $11.6(4)$ & $13.4(4)$ & $10.0(4)$ & & 10.7 (11) & & \\
\hline closed & $27.8(76)$ & $30.1(13)$ & $29.7(13)$ & $30.1(13)$ & $27.0(15)$ & $25.6(15)$ & $31.2(334)$ & & & 25 \\
\hline
\end{tabular}

\subsection{Linear Regression Model for Open and Tilted Windows}

For open and tilted windows, apart from the position of the window, the room type and the age of the building turned out to be highly significant parameters. In living rooms the outdoor-indoor differences were slightly lower $(-1 \mathrm{~dB})$ and in kitchen/dining rooms clearly lower $(-5 \mathrm{~dB})$ than in bedrooms. This can be explained by more absorbing materials in bedrooms (bed, curtains, carpets), which is normally also true for living rooms (sofa, curtains, carpets). Kitchen/dining rooms generally have more sound-reflecting surfaces. Bigger rooms with the same incoming sound power have a lower sound level inside and therefore a larger indoor-outdoor difference, which the statistical model shows for rooms with $60-150 \mathrm{~m}^{3}(+1.1 \mathrm{~dB})$. The volumes of living rooms and kitchen/dining rooms are generally bigger than those of sleeping rooms. The age of the building effect shows the counter-intuitive trend that newer buildings have slightly lower outdoor-indoor differences $(20-40$ years: $+1.7 \mathrm{~dB}$, $>40$ years: $+1.9 \mathrm{~dB}$ ). It is expected that newer buildings have greater sound insulation. Nevertheless, the effect of the age can be explained: it might reflect the bigger window sizes of newer buildings. Unfortunately, the window size was not measured. For future studies, it is suggested to collect this important parameter. The distance from the microphone inside to the window does not significantly affect the sound level differences between the inside and outside, which supports the assumption of a diffuse sound field.

A small influence on the outdoor-indoor differences is attributed to the mean sound level outdoors. It has to be assumed that this finding indicates a limitation of the measurement concept. Despite removing data points without the outdoor-indoor correlation, there might be some measurements with disturbing noises inside that influence the median difference. This effect is bigger in case of closed windows, as described in the next section.

A sensitivity analysis based on a model with all data (including four outliers) provided similar results (same parameters and significance levels, only slightly different coefficients).

\subsection{Linear Regression Model for Closed Windows}

The statistical analysis for the closed windows dataset showed a high correlation of the outside sound pressure level on the outdoor-indoor difference. This might be explained by the fact that buildings close to noisy streets have more often windows with a high level sound insulation, especially in Switzerland where extensive noise mitigation programs have been realized in the past decade. Additionally, for the last 30 years Swiss building regulations have specified minimal sound insulation depending on the outside noise level [44]. However it must be assumed that this strong influence indicates (at least partially) a limitation of the measurement procedure, as high levels of sound insulation cannot be exactly measured with typical levels of outside traffic noise. For that purpose, alternative methods with artificial source, i.e., a loudspeaker, should be considered. In addition, it has to be kept in mind that rooms with high levels of sound insulation less likely comply with inclusion criteria in the statistical analysis due to a lack of correlation between the sound levels outdoors and indoors. Hence, it must be concluded that the dataset for closed windows is likely to be unbalanced, with a tendency to underestimate the real difference in level.

Other significant parameters were the glazing composition, the material of the window frame, the existence of window gaskets, and the number of windows, however with a rather small overall effect. The linear model indicates that vinyl and metal window frames have a higher $(+1.9 \mathrm{~dB}(\mathrm{~A}))$ 
outdoor-indoor difference compared to wooden window frames. This is not as would be expected, as new wooden windows typically exhibit a higher sound insulation due to the additional mass and other construction details. However, wooden window frames are probably more often older, as vinyl window frames are more common these days. Older window frames might often be distorted, especially in case of wooden frames, and therefore not completely airtight and less sound insulated.

Windows without window gaskets have lower $(-2.4 \mathrm{~dB}(\mathrm{~A}))$ outdoor-indoor differences, as would be expected due to a reduced sound insulation. The more windows there are, the lower is the outdoor-indoor difference $(-0.8 \mathrm{~dB}(\mathrm{~A}) \cdot$ number of windows). The façade normally has clearly higher sound insulation than windows. More windows will consequently have a negative effect on the overall sound insulation.

Sensitivity analyses based on a model with all data (including two outliers) provided slightly different results: in this case only the outside sound pressure level had a significant effect. A closer look at the two outliers shows that the outdoor-indoor difference is below $18 \mathrm{~dB}(\mathrm{~A})$, although there are no parameters indicating very low sound insulation (both having gaskets, double and triple glazing, etc.). Therefore, we do not trust the two measurements with a very low outdoor-indoor difference.

\section{Relevance and Applicability}

The proposed measurement and analysis concept was proven to be suitable to determine differences between sound levels outdoors and indoors for open and tilted windows. Limitations are the short measurement time of only 3 min and the fact that these took often place in the evening hours when the participants were at home. However, the measurements were performed under observation and periods with interfering sounds were excluded. As it is not the intention of the measurement procedure to establish representative long-term sound exposure levels, such short but fully controlled measurements are expected to be advantageous compared to long-term measurements, where outside noise is mixed with often dominant interior noises. Therefore, we are convinced that the procedure yielded reliable outside-inside differences. For closed windows however, using the present road traffic as sound source instead of artificial source, turned out to be a limiting factor, causing a tendency to underestimate the real sound insulation for façades meeting higher building standards. The resulting outside-inside differences seem applicable in any case, however they should be interpreted as a safe side estimate.

All measurements for this study were performed in Switzerland. Even though the measurement sites were not specifically selected to reproduce an average Swiss building standard, with measurements in over 100 buildings we assume that the results are representative for situations with high road traffic noise exposure in Switzerland. The comparison with other studies, as shown in Table 5, reveals a certain consensus on the insulation effect of open or tilted windows. As the dominant sound path goes through the opening, window as well as façade properties are of minor influence. Other influencing factors, such as the angle of sound incidence or the size of the opening, cause a variation of results. The latter however still lies within 1-2 $\mathrm{dB}(\mathrm{A})$, a range which is comparable to other uncertainties in source and propagation modeling. Consequently it can be concluded that the results for open and tilted windows presented in this study have general validity and might be applied in other countries also. However, the situation looks different in the case of closed windows. Here, the building standard has a major influence on the outcome and the range of possible types of sound insulation is much broader. It has also to be taken into account that in many countries the requirements for façade sound insulation and quality of windows depend on the outdoor noise level. Therefore, the range of applications of the presented results should be restricted to countries with a comparable building standard to Switzerland, such as for example most countries in Northern Europe.

\section{Conclusions}

A measurement method is presented that allows to assess the sound insulation of buildings based on simultaneous measurements of traffic noise outdoors and indoors. On that basis comprehensive 
measurements have been performed to derive representative level differences outside to inside for open, tilted and closed windows. It could be shown that the measurement and analysis procedure yields reliable results for open and tilted windows. However in the case of situations with closed windows and high sound insulations sometimes the signal-to-noise ratio, using existing traffic noise instead of an artificial sound source, is a limiting factor.

Based on additional parameters such as the orientation towards the source, floor and room type as well as sound insulation characteristics a statistical model was established to predict outside-inside level differences. In combination with noise mappings that describe noise levels outside of buildings this model can be used to estimate the sound exposure inside of dwellings, an information which is mandatory to assess sleep disturbance and can also be applied in epidemiological or socio-acoustic studies.

Acknowledgments: We are grateful to all of the participants for letting us carry out measurements at their homes. The study was undertaken within the SIAS project, which is funded by the Swiss Federal Office for the Environment FOEN. The authors gratefully acknowledge the financial support from the FOEN.

Author Contributions: J.M.W. (project leader), M.B., C.C. and M.R. conceived and designed the experiments; A.P. performed the experiments; B.L. analyzed the data; M.R. and M.F. supported the establishment of the statistical models; D.V. and U.M. contributed data; M.H. was responsible for spatial analysis in GIS; B.L. and J.M.W. wrote the paper.

Conflicts of Interest: The authors declare no conflict of interest. The founding sponsors had no role in the design of the study; in the collection, analyses, or interpretation of data; in the writing of the manuscript, and in the decision to publish the results.

\section{References}

1. Recio, A.; Linares, C.; Banegas, J.R.; Díaz, J. Road traffic noise effects on cardiovascular, respiratory, and metabolic health: An integrative model of biological mechanisms. Environ. Res. 2016, 146, 359-370.

2. Pirrera, S.; Valck, E.D.; Cluydts, R. Field study on the impact of nocturnal road traffic noise on sleep: The importance of in- and outdoor noise assessment, the bedroom location and nighttime noise disturbances. Sci. Total Environ. 2014, 500-501, 84-90.

3. Frei, P.; Mohler, E.; Röösli, M. Effect of nocturnal road traffic noise exposure and annoyance on objective and subjective sleep quality. Int. J. Hyg. Environ. Health 2014, 217, 188-195.

4. Basner, M.; Babisch, W.; Davis, A.; Brink, M.; Clark, C.; Janssen, S.; Stansfeld, S. Auditory and non-auditory effects of noise on health. Lancet 2014, 383, 1325-1332.

5. Brink, M. A review of potential mechanisms in the genesis of long-term health effects due to noise-induced sleep disturbances. In Proceedings of the INTER-NOISE 2012, New York, NY, USA, 19-22 August 2012.

6. Eze, I.C.; Foraster, M.; Schaffner, E.; Vienneau, D.; Héritier, H.; Rudzik, F.; Thiesse, L.; Pieren, R.; Imboden, M.; von Eckardstein, A.; et al. Long-term exposure to transportation noise and air pollution in relation to incident diabetes in the SAPALDIA study. Int. J. Epidemiol. 2017, 46, 1115-1125.

7. Héritier, H.; Vienneau, D.; Foraster, M.; Eze, I.C.; Schaffner, E.; Thiesse, L.; Rudzik, F.; Habermacher, M.; Köpfli, M.; Pieren, R.; et al. Transportation noise exposure and cardiovascular mortality: A nationwide cohort study from Switzerland. Eur. J. Epidemiol. 2017, 32, 307-315.

8. Amundsen, A.H.; Klaeboe, R.; Aasvang, G.M. The Norwegian Facade Insulation Study: The efficacy of facade insulation in reducing noise annoyance due to road traffic. J. Acoust. Soc. Am. 2011, 129, 1381-1389.

9. Amundsen, A.H.; Klaeboe, R.; Aasvang, G.M. Long-term effects of noise reduction measures on noise annoyance and sleep disturbance: The Norwegian facade insulation study. J. Acoust. Soc. Am. 2013, 133, 3921-3928.

10. Foraster, M.; Künzli, N.; Aguilera, I.; Rivera, M.; Agis, D.; Vila, J.; Bouso, L.; Deltell, A.; Marrugat, J.; Ramos, R.; et al. High blood pressure and long-term exposure to indoor noise and air pollution from road traffic. Environ. Health Perspect. 2014, 122, 1193-1200.

11. Schreckenberg, D. Exposure-response relationship for railway noise annoyance in the Middle Rhine Valley. In Proceedings of the INTER-NOISE and NOISE-CON Congress and Conference Proceedings, Innsbruck, Austria, 15-18 September 2013. 
12. Öhrström, E.; Skånberg, A.; Svensson, H.; Gidlöf-Gunnarsson, A. Effects of road traffic noise and the benefit of access to quietness. J. Sound Vib. 2006, 295, 40-59.

13. Griefahn, B.; Schuemer-Kohrs, A.; Schuemer, R.; Moehler, U.; Mehnert, P. Physiological, subjective, and behavioural responses to noise from rail and road traffic. Noise Health 2000, 3, 59-71.

14. Röösli, M.; Vienneau, D. Epidemiological exposure assessment. In Epidemiology of Electromagnetic Fields-An Application of Environmental Epidemiological Methods; Röösli, M., Ed.; CRC Press, a Taylor \& Francis Company: Boca Raton, FL, USA, 2014; pp. 37-58.

15. Ryan, M.; Lanchester, M.; Pugh, S. Noise Reduction through Facades with Open Windows. Paper Number 37. In Proceedings of the ACOUSTICS, Gold Coast, Australia, 2-4 November 2011.

16. Müller, U. Sound level measurement of aircraft and vehicle noise, simultaneously recorded at facades and the sleeper's ear. In Proceedings of the Euronoise 2006, Tampere, Finland, 30 May-6 June 2006.

17. Basner, M.; Müller, U.; Samel, A. Nachtfluglärmwirkungen (Band 2): Methodik, Akustik. DLR-Forschungsbericht 2004-08/D; Technical Report; Institut für Luft- und Raumfahrtmedizin des DLR: Köln, Germany, 2004.

18. Müller, U.; Basner, M.; Samel, A. DEUFRAKO/RAPS—Railway Noise (and Other Modes) Annoyance, Performance, Sleep. Wirkungsorientierte Bewertung Unterschiedlicher Verkehrslärmarten. Teilvorhaben DLR: Metaanalyse und Feldstudie. Abschlussbericht; Technical Report; Deutsches Zentrum für Luft- und Raumfahrt: Cologne, Germany, 2010.

19. Jansen, G.; Linnemeier, A.; Nitzsche, M. Methodenkritische Überlegungen und Empfehlungen zur Bewertung von Nachtfluglärm. Z. Lärmbekämpfung 1995, 42, 91-106.

20. BUWAL. Belastungsgrenzwerte Für den Lärm der Landesflughäfen. Schriftenreihe Umwelt Nr. 296, 1998. Available online: https://www.bafu.admin.ch/bafu/de/home/themen/laerm/publikationen-studien/ publikationen/belastungsgrenzwerte-laerm-landesflughaefen.html (accessed on 3 March 2017).

21. Maschke, C.; Volz, R.; Jakob, A.; Augustin, E. Pegeldifferenzen Gekippt-Geöffneter Fenster bei FluglärmMessungen nach DIN EN ISO 140-5 Gesamt-Lautsprecher-Verfahren; Deutsche Gesellschaft für Akustik e.V (DEGA) (German Society for Acoustics (DEGA): Berlin, Germany, 2010.

22. EEA. Good Practice Guide on Noise Exposure and Potential Health Effects; Technical Report; European Environment Agency: Copenhagen, Denmark, 2010. Available online: https://www.eea.europa.eu/ publications/good-practice-guide-on-noise (accessed on 16 August 2017).

23. Granzotto, N.; Bettarello, F.; Ferluga, A.; Marsich, L.; Schmid, C.; Fausti, P.; Caniato, M. Energy and acoustic performances of windows and their correlation. Energy Build. 2017, 136, 189-198.

24. Buratti, C. Indoor noise reduction index with open window. Appl. Acoust. 2002, 63, 431-451.

25. Jean, P. Sound transmission through opened windows. Appl. Acoust. 2009, 70, 41-49.

26. Tong, Y.G.; Tang, S.K.; Kang, J.; Fung, A.; Yeung, M.K.L. Full scale field study of sound transmission across plenum windows. Appl. Acoust. 2015, 89, 244-253.

27. Licitra, G.; Fredianelli, L.; Petri, D.; Vigotti, M.A. Annoyance evaluation due to overall railway noise and vibration in Pisa urban areas. Sci. Total Environ. 2016, 568, 1315-1325.

28. Pabst, F. Massnahmenkonzept zum Zürcher Flughafen-Index (ZFI). Projektgruppe "Raumentwicklung/ Wohnqualität". Fragenbeantwortung im Rahmen der Studie "Bauqualität und Schalldämmung"; Volkswirtschaftsdirektion Kanton Zürich: Zürich, Switzerland, 2009.

29. Scamoni, F.; Scrosati, C. The facade sound insulation and its classification. In Proceedings of the Forum Acusticum, Kraków, Poland, 7-12 September 2014; p. 6.

30. Secchi, S.; Astolfi, A.; Calosso, G.; Casini, D.; Cellai, G.; Scamoni, F.; Scrosati, C.; Shtrepi, L. Effect of outdoor noise and façade sound insulation on indoor acoustic environment of Italian schools. Appl. Acoust. 2017, 126, 120-130.

31. Pinho, P.G.; Pinto, M.; Almeida, R.M.S.F.; Lopes, S.M.; Lemos, L.T. Aspects concerning the acoustical performance of school buildings in Portugal. Appl. Acoust. 2016, 106, 129-134.

32. Puglisi, G.E.; Cutiva, L.C.C.; Pavese, L.; Castellana, A.; Bona, M.; Fasolis, S.; Lorenzatti, V.; Carullo, A.; Burdorf, A.; Bronuzzi, F.; et al. Acoustic Comfort in High-school Classrooms for Students and Teachers. Energy Procedia 2015, 78, 3096-3101.

33. Dongre, A.R.; Patil, A.P.; Wahurwagh, A.J.; Kothari, A.; Burchundi, K.; Manohare, M.P. Acoustical characteristics of classrooms of tropical climate. Appl. Acoust. 2017, 121, 46-55.

34. Sala, E.; Rantala, L. Acoustics and activity noise in school classrooms in Finland. Appl. Acoust. 2016, $114,252-259$. 
35. Mealings, K.T.; Buchholz, J.M.; Demuth, K.; Dillon, H. Investigating the acoustics of a sample of open plan and enclosed Kindergarten classrooms in Australia. Appl. Acoust. 2015, 100, 95-105.

36. Locher, B.; Piquerez, A.; Habermacher, M.; Ragettli, M.; Röösli, M.; Brink, M.; Cajochen, C.; Probst Hensch, N.; Foraster, M.; Wunderli, J. A statistical model to predict sound level differences between in- and outdoors. In Proceedings of the ICBEN 2017, Zürich, Switzerland, 18-22 June 2017.

37. Karipidis, I.; Vienneau, D.; Habermacher, M.; Köpfli, M.; Brink, M.; Probst-Hensch, N.; Röösli, M.; Wunderli, J.M. Reconstruction of historical noise exposure data for environmental epidemiology in Switzerland within the SiRENE project. Noise Mapp. 2014, 1, doi:10.2478/noise-2014-0002.

38. Brink, M.; Schreckenberg, D.; Vienneau, D.; Cajochen, C.; Wunderli, J.M.; Probst-Hensch, N.; Röösli, M. Effects of scale, question location, order of response alternatives, and season on self-reported noise annoyance using icben scales: A field experiment. Int. J. Environ. Res. Public Health 2016, 13, 1163, doi:10.3390/ijerph13111163.

39. Schlatter, F.; Piquerez, A.; Habermacher, M.; Ragettli, M.; Röösli, M.; Brink, M.; Cajochen, C.; Probst-Hensch, N.; Foraster, M.; Wunderli, J. Validation of large scale noise exposure modelling by long-term measurements. Noise Mapp. 2017, 4, 75-86.

40. Tukey, J. Exploratory Data Analysis; Addison-Wesley Pub. Co.: Reading, MA, USA, 1977.

41. Kephalopoulos, S.; Paviotti, M.; Anfosso-Lédée, F. Common Noise Assessment Methods in Europe (CNOSSOS—EU); Technical Report; European Union: Brussels, Belgium, 2012.

42. Kötz, W.D. Zur Frage der effektiven Schalldämmung von geöffneten Fenstern. Z. Lärmbekämpfung 2004, $51,21-26$.

43. Buratti, C.; Belloni, E.; Moretti, E. Façade noise abatement prediction: New spectrum adaptation terms measured in field in different road and railway traffic conditions. Appl. Acoust. 2014, 76, 238-248.

44. SIA 181. Schallschutz im Hochbau; Schweizer Norm SN 520 181; Schweizerischer Ingenieur- und Architektenverein: Zürich, Switzerland, 2006.

(C) 2018 by the authors. Licensee MDPI, Basel, Switzerland. This article is an open access article distributed under the terms and conditions of the Creative Commons Attribution (CC BY) license (http:/ / creativecommons.org/licenses/by/4.0/). 